\title{
Aerogel/epoxy thermal coatings for carbon fibre reinforced plastic substrates
}

\author{
Suryanarayanan Krishnaswamy ${ }^{1}$, Hrushikesh Abhyankar ${ }^{2}$, Veronica Marchante ${ }^{3}$, Zhaorong \\ Huang $^{4}$ and James Brighton ${ }^{5}$
}

\footnotetext{
${ }^{1} \mathrm{PhD}$ Researcher, Advanced Vehicle Engineering Centre, Cranfield University, UK. s.krishnaswamy@cranfield.ac.uk

${ }^{2}$ Lecturer, Advanced Vehicle Engineering Centre, Cranfield University, UK.

h.a.abhyankar@cranfield.ac.uk

${ }^{3}$ Research Fellow, Advanced Vehicle Engineering Centre, Cranfield University, UK. v.marchanterodriguez@cranfield.ac.uk

${ }^{4}$ Senior Research Fellow, Surface Engineering Precision Institute- Cranfield University, UK. Z.Huang@cranfield.ac.uk

${ }^{5}$ Senior Lecturer. Advanced Vehicle Engineering Centre, Cranfield University, UK. j.1.brighton@cranfield.ac.uk
}

\section{Corresponding Author:}

Suryanarayanan Krishnaswamy

School of Aerospace, Transport and Manufacturing, Cranfield University

Email: s.krishnaswamy@cranfield.ac.uk

\begin{abstract}
The present work studies an aerogel/epoxy composite that was dip coated onto a carbon fibre substrate by adding the aerogel at the 1 hour and the 1.5 mark of the epoxy cure. Both coatings show decrease in thermal conductivity values (39\% and $47 \%$ respectively) when compared to a pure epoxy coating. The coatings' reflectance spectra also provided further evidence for the existence of the nano-pores within the aerogel particles. The aerogel coating was modelled using material properties from literature and solved using finite element methods. The model, which validated using experimental data, was then used to predict the coating's performance in cyclic thermal loads. Additionally, coatings on a single surface- top and bottom; were also modelled and compared with the double coating system wherein it was seen that the double coating system had the lowest rate of temperature change and fluctuations at steady-state in contrast to the bottom coating which, showed the fastest drop in temperature as well as the highest fluctuations at steady state conditions. The performance of the top coating was in the middle.
\end{abstract}

Keywords: Aerogel, composites, thermal coatings, finite element modelling, epoxy 


\section{Introduction}

Carbon composites, like carbon/epoxy and carbon/carbon (graphite) exhibit a high strength to weight ratio and excellent retention of high temperature properties such as modulus and strength in an inert atmosphere, high thermal conductivity and shock resistance, low coefficient of thermal expansion (CTE) and recession in ablative environments [1,2,3]. Additionally, composite materials are resistant to corrosion and fatigue in most cases [4], making them an ideal choice for various high performance applications in the aerospace and automotive industry (amongst many others). However these materials are limited by their high cost, low impact resistance, low fracture toughness and low ductility [5,4]. The operating temperatures of the polymers also limit the polymer matrix composites' usage. From the examples given in Peel's [5] work, it is seen that only two (out of five) polymers have their maximum operating temperatures in excess of $200^{\circ} \mathrm{C}$ : thermoset polyamides and semi-thermoplastic polyether ether ketone (PEEK). Therefore to increase the service life of composite materials in certain applications that require operation at higher temperatures, the use of a coating is needed.

The use of aerogels as a filler material is a promising route for future thermal coatings. Aerogels are jellies whose liquid has been removed with very minimal or no shrinkage [6]. The resultant material exhibits, amongst others, very low thermal conductivity $(0.012 \mathrm{~W} /(\mathrm{m} \mathrm{K}))$, low density $\left(3 * 10^{3}-1 * 10^{5} \mathrm{~g} / \mathrm{m}^{3}\right)$, low dielectric constant (1.1-2.0), high specific surface area (500-1200 $\mathrm{m}^{2} / \mathrm{g}$ ) and low refraction index $(1.05)[7,8,9]$ values. However, the material's structure, which contributes to the properties discussed above, results in a very limited mechanical strength [10]. Therefore, strengthening mechanisms include the use of polymer binders/matrices as discussed by Schmidt \& Schwertfeger[11] which could offer potential routes to aerogel coating applications. According to Zhao et al. [12] aerogel/epoxy composites have thermal conductivities as low as $0.105-0.175 \mathrm{~W} /(\mathrm{m} * \mathrm{~K})$ and the relationship between the property and the weight fraction of the aerogel is not linear. Their study also showed that bigger aerogel particles $(0.2-2 \mathrm{~mm})$ showed better thermal properties than smaller particles $(<0.2 \mathrm{~mm})$. Williams et al. [13] discussed various examples of aerogels in different thermoplastic matrices such as polyamides and polyolefins with promising results. A reduction in the thermal conductivity was also observed with the addition of silica aerogel into a poly (ethylene-covinyl acetate) (EVA) composite film [14]. In another work, Achar \& Procopio[15] compared waterborne acrylic-styrene latex and epoxy systems with different amounts of aerogel and hollow glass microspheres as fillers. They showed that the acrylic-based coatings performed better than their epoxy counterparts and that aerogel had higher thermal conductivity compared to glass microspheres (in acrylic polymers), which according to the authors, could be due to the polymer intrusion into the pores of the aerogel. Additionally, the authors also commented on the high viscosity of the resin which resulted in poor processing. The infiltration of the resin in the pores of the aerogel is also discussed in [9]. This effect was further noted in the work by Vahtrus et al. [16] wherein the authors noted an increase in the thermal conductivity of aerogel/epoxy composites due to the filling of the resin into the pores of the aerogel. Therefore, works such as those of Gupta \& Ricci [17] and Ge et al. [8] looked at different processing methods/materials to incorporate the aerogel in an epoxy matrix with the former reducing the viscosity of epoxy and the latter using solid epoxy powder. Another limitation of using resins like epoxy is the formation of bubbles during the processing (mixing) of the composite. This is highlighted in [18] wherein the influence of stirring speed and time on the water absorption and hence, the trapped air bubble size were investigated. 
The epoxy matrices also usually soften, distort and collapse between $60^{\circ} \mathrm{C}$ and $150^{\circ} \mathrm{C}$ [19]. Therefore, traditional processing techniques like plasma spraying and EB-PVD are not possible since the low thermal stability of these organic resins demands processing temperatures less than their glass transition $\left(150^{\circ} \mathrm{C}-200^{\circ} \mathrm{C}\right)$ and/or decomposition temperature [20]. However since, the highest temperature considered in the present work is $100^{\circ} \mathrm{C}$, a liquid epoxy system was chosen as a binding material in the present work because of the polymer's wide use in composite materials, adhesives and moulding compounds[21,22,23].

The present work evaluates the applicability of aerogel/epoxy coatings on carbon fibre reinforced polymer (CFRP) substrates wherein its aim was to increase the latter's thermal performance. The thermal conductivity of the coatings was determined in relation to a pure epoxy coating. Additionally, a finite element (FE) model of the coating and substrate was built to simulate the system's performance thereby allowing a greater understanding of the material's behaviour under different loads/environments. In the following section, details on the methodology to process the coating, the experimental techniques and the FE model are described. The experimental results along and the output of the validated model subjected to cyclic loads are then presented and subsequently discussed.

\section{Materials and Methods}

\subsection{Sample Preparation}

The carbon fibre substrates were prepared using a multiaxial ACG (Advanced Composites Group Ltd, UK) MTM46/CF6657-38\%RW-DC prepreg cut and assembled on a flat mould to a thickness of around $5 \mathrm{~mm}$. These samples were initially cured at $80^{\circ} \mathrm{C}$ for 1 hour using resin film infusion (RFI) by ramping up the temperature from $20^{\circ} \mathrm{C}$ to $80^{\circ} \mathrm{C}$ at $3^{\circ} \mathrm{C} / \mathrm{min}$. They were then put in an autoclave at $120^{\circ} \mathrm{C}$ for 1 hour using $50 \mathrm{psi}\left(80^{\circ} \mathrm{C}\right.$ to $120^{\circ} \mathrm{C}$ at $\left.3^{\circ} \mathrm{C} / \mathrm{min}\right)$. The top surface of the composite was then cleaned using a 400 grit paper, washed and dried.

To test the material, the composite plate was cut into samples of $40 \times 40 \mathrm{~mm}^{2}$ using a rotating blade. After which, the surface of samples used as substrates for the coating were roughened using a 120 grit sand paper. All the samples were then subsequently washed and dried.

Aerogel/epoxy coatings for the CFRP substrate were processed using aerogel particles and an epoxy network. For the matrix, RS-M135 (PRF composites, UK) epoxy formulation was mixed in a 10:3 ratio (by weight) with a custom hardener that was in turn, a 2:1 (also by weight) mixture of RS-MH137 and RS-MH134 (both by PRF composites). Enova Aerogel IC3110 (Cabot Corporation, USA) were the silica aerogel particles used. Additionally, a wetting agentBYK-P 9920 (BYK-Chemie, Germany) was used to increase the wetting of the aerogel particles with the matrix binder.

The first batch was a plain resin coating without the aerogel particles. To prepare this set of samples, the epoxy and the hardener were mixed in the ratio described previously and the mixture was degassed in a vacuum oven for around 30 mins. After degassing, the CFRP substrates were dipped into the resin to form a coating around it and the new coated composite was left to cure at room temperature for a minimum of 48 hours. For the second batch, $3 \%$ (of the total weight of the coating) wetting agent was stirred into the resin before the addition of the hardener and the resulting solution was degassed in a vacuum oven for 1 hour. After which, $3 \%$ (by weight of the resin system) of the aerogel was added and manually stirred into the 
solution before dip coating the CFRP substrates and curing, again for a minimum of 48 hours. The preparation of the final batch of the coating was identical to the second batch with the only exception being the time of addition of the aerogel particles. Here, the epoxy solution (with the wetting agent) was left in the vacuum oven for 1.5 hours before the addition of the aerogel. The coating process and the cure time were similar to the previous batches.It must be noted that the coated samples were further trimmed to $30 \times 30\left(\mathrm{~mm}^{2}\right)$ to remove the excess coating aggregated on the sides of the samples.

For simplicity, the samples coated with the pure epoxy are named $\mathrm{P}(\mathrm{x})$ and samples with the aerogel/epoxy coating are named $1 \mathrm{C}(\mathrm{x})$ and $1.5 \mathrm{C}(\mathrm{x})$ depending upon the time of aerogel addition (1 hour and 1.5 hours respectively).

\subsection{Scattering Coefficient}

The reflection spectra of the samples were measured using a Jasco V-670 spectrophotometer fitted with an integrating sphere of $60 \mathrm{~mm}$ diameter using a fluro-polymer based spectralon as a calibration standard. The scan range was set between $200 \mathrm{~nm}-1500 \mathrm{~nm}$ with a scan speed of $400 \mathrm{~nm} / \mathrm{min}$.

\subsection{Thermal conductivity}

To measure the thermal conductivity of the samples, Equation 1 was made use of which describes the one dimensional heat conduction through a plane wall under steady state conditions as given in [24,p.378] wherein $k$ is the thermal conductivity of the sample, $Q$ is the rate of heat flow (conduction) across the sample, $A$ is the cross sectional area, $\Delta T$ is the temperature difference across the sample and $L$ is the thickness.

$$
\begin{aligned}
& k=\frac{Q / A}{\Delta T / L} \\
& \text { Equation 1 }
\end{aligned}
$$

The cross sectional area $(A)$ and the thickness $(L)$ of the samples were determined using a line gauge. The temperature difference across the sample $(\Delta T)$ was measured at three different temperatures- $50^{\circ} \mathrm{C}, 75^{\circ} \mathrm{C}$ and $100^{\circ} \mathrm{C}$ wherein the heat was provided by a heater connected to a Eurotherm 2216e (Schneider Electric, United Kingdom) controller. For each temperature, the system was allowed to stabilise for 1 hour (to achieve steady state) before recording the temperature at the top and the bottom of the sample using cement on polyimide thin film thermocouples supplied by TC Direct (UK). A schematic diagram and a picture of the setup are shown in Figure 1 (a) and (b) respectively.

To calculate the heat flow across the sample (Q), a material of known thermal conductivity value (a standard) was used and the temperature at the top and the bottom of the sample was recorded. Since the thermal conductivity was known, Q could be calculated at different temperatures using the Equation 1. Three different runs at the above-mentioned temperature were conducted and the average $Q$ value for each temperature was used for subsequent thermal conductivity calculations for the samples. The standard used was a lead zirconate titanium (PZT) disc (PC 8) by Morgan Matroc (UK).

To calculate the thermal conductivity of the samples, 5 specimens for each samples were utilised wherein the cross sectional area for each specimen was calculated using the average of three separate length and breadth measurements. Similarly the thickness used was also the 
average of three measurements. Using the average values, the thermal conductivity for each of the samples was determined at the three different temperatures using the pyro rig. Finally for each temperature, the average of the 5 specimens was used as the thermal conductivity of that particular material.

\subsection{Finite element model}

A finite element (FE) model was built using LS-PrePost- 4.3dp and solved in LS-DYNA. The geometry of the substrate was a rectangular plate of $0.03 \times 0.03 \times 0.005 \mathrm{~m}^{3}$ which was similar to the experimental samples. The coating was also modelled as rectangular boxes with dimensions of $0.03 \times 0.03 \times 0.0007 \mathrm{~m}^{3}$ above and/or below the CFRP substrate. The thickness of the coating modelled was the average value of the dip-coated experimental samples.

\subsubsection{Material Card}

Since the model was subjected to thermal analysis, only the thermal material cards were defined. The substrate's properties were defined using the MAT_THERMAL_ORTHOTROPIC card. The coating was modelled using the MAT_THERMAL_ISOTROPIC card because of the homogenous distribution of aerogel particles within the epoxy matrix. The properties of the substrate and coating used are presented in Table 1. The coating's thermal conductivity was the experimental value of the bulk material determined previously [25]. The other properties of the coating were calculated using the rule of mixtures and individual properties of aerogel and epoxy . The volume fraction of aerogel used in the rule of mixture was 0.21 determined from the densities of the resin and aerogel in Table 1.

\subsubsection{Elements and Meshing}

The work of Shapiro [26] suggests the use of 8 node brick elements as one of the element types that could be used in thermal analysis. Hence, the coating and substrate were modelled using fully integrated quadratic 8 node solid elements with nodal rotations $($ ELFORM $=3)$. This element formulation gives accurate results in small strain conditions [27].

\subsubsection{Loading and Simulation}

The temperature was applied on the nodes at the top of the specimen through the BOUNDARY_TEMPERATURE_SET card using DEFINE_CURVE. The initial temperature was set to $23^{\circ} \mathrm{C}$ for all the nodes with the INITIAL_TEMPERATURE card. Because the material properties for the substrate and coating are assumed to be constant with respect to time and temperature, a linear transient analysis using a diagonal scaled conjugate gradient iterative solver (SOLVER = 3) was performed. An iterative solver was used due to its higher efficiency compared to a direct solver (LS-DYNA user manual [28]). The models also used a fully implicit time integration parameter to calculate the thermal timestep.

The coated models additionally made use of the CONTACT_AUTOMATIC_SURFACE_TO_SURFACE_SMOOTH card with the THERMAL option for both surfaces. Here, the heat transfer conductance was 100; an arbitrarily chosen high value with the minimum and maximum lengths to be 0.0002 and 1 respectively. 


\section{Results}

\subsection{Scattering coefficient}

The scattering plot for the samples is shown in Figure 2. It is seen that both the aerogel samples have identical curves and show a peak in the $200 \mathrm{~nm}-250 \mathrm{~nm}$ interval. The higher prominence of the aerogel composites peak near the 200nm wavelength was also observed by Fernandes et al. [29] in their aerogel samples, thereby providing evidence for the material's existence in the coatings of the present work. Further, the pure epoxy coating shows an increase in this region as well, but the scattering intensity is not as high as the aerogel coated samples and the carbon fibre substrate does not exhibit this phenomenon thereby suggesting this to be an effect of the coating and in particular, that of the aerogel particles.

\subsection{Heat flow across the sample}

Since the thermal conductivity values for each of the samples were calculated at three different temperatures: $50^{\circ} \mathrm{C}, 75^{\circ} \mathrm{C}$ and $100^{\circ} \mathrm{C}$, the heat flow across the standard at these temperatures had to be determined using Equation 1. The results are given in Table 2 wherein the diameter and the thickness of the standard were $0.024 \mathrm{~m}$ and $0.002 \mathrm{~m}$ respectively. Further, the thermal conductivity of the standard used was $1.1 \mathrm{~W} /(\mathrm{m} * \mathrm{~K})$, as given in[30].

The average of the three values calculated for each temperature was then used in the subsequent thermal conductivity calculations.

\subsection{Thermal conductivity}

The calculated thermal conductivity values along with the standard deviation $(\sigma)$ and temperature difference between $\mathrm{T} 1$ and $\mathrm{T} 2$ are shown in Table 3 for all the samples. For the purpose of comparison, the average thermal conductivity values for each sample at the given temperature was also calculated and shown in the table.

The thermal conductivity values for each sample are almost constant in the measured temperature interval. However, there is a reduction between the pure epoxy and the aerogel/epoxy samples; $0.69 \mathrm{~W} /(\mathrm{m} * \mathrm{~K})$ for the pure epoxy coating at $75^{\circ} \mathrm{C}$ to $0.41 \mathrm{~W} /(\mathrm{m} * \mathrm{~K})$ and $0.36 \mathrm{~W} /\left(\mathrm{m}^{*} \mathrm{~K}\right)$ for the samples $1 \mathrm{C}$ and $1.5 \mathrm{C}$ respectively. This indicates a positive influence of the aerogel particles on the thermal insulation performance of the coating. Between the aerogel coatings, $1.5 \mathrm{C}$ shows marginally lower values when compared to $1 \mathrm{C}$. This improvement in insulation capability of the former is due to the curing epoxy being more viscous during aerogel addition. However, it must be noted that a more viscous resin would result in a greater degree of difficulty whilst coating complex shapes.

\section{Modelling}

\subsection{Mesh optimisation and validation}

To identify the most efficient element size, a model of the substrate was subjected to a constant temperature of $75^{\circ} \mathrm{C}$ through all the nodes at the top of the geometry for 150 seconds. A random element towards the centre of the bottom surface was chosen and its temperature as a function of time was plotted and compared between different element sizes; the results are shown in Figure 3. It is seen that regardless of the size of the mesh, all models attained steady state within 100 seconds. Mesh sizes lower than $0.0001 \mathrm{~m}$ were not considered due to their complexity and 
resource constraints. The hybrid mesh model consisted of rectangular elements whose size was $0.001 \mathrm{~m}$ in the plane perpendicular to the heat flow ( $\mathrm{x}$ and $\mathrm{y}$ axes) and $0.0001 \mathrm{~m}$ along the direction of the heat flow ( $\mathrm{z}$ axis).

From the results of Figure 3, which shows the temperature of the element in the bottom surface as a function of time, it is seen that $0.0001 \mathrm{~m}$ and $0.00025 \mathrm{~m}$ element sizes attained steady state conditions earlier and at lower temperatures than the coarser meshes, which displayed identical results. The results of the $0.01 \mathrm{~m}$ mesh also showed some difference from the other models especially at the beginning; this is thought to be due to the coarse nature of the mesh which resulted in the presence of the same element for both, top and bottom surfaces and would have resulted in the cross-sectional heat transfer occurring through a single element. Hence, this mesh is not considered further. When considering the steady state temperatures attained by the models (shown in Table 4), it is seen that none of them reached the input temperature of $75^{\circ} \mathrm{C}$. However, because no losses were defined in the original model, it is believed that temperatures at the bottom should ultimately reach the input temperature. Therefore, the convergence tolerance of the thermal solver (CGTOL in CONTROL_THERMAL_SOLVER) was decreased to reduce the error in the solution and hence, attain a more representative result. To find the most effective tolerance value, the $0.001 \mathrm{~m}$ model was simulated with progressively smaller tolerance values starting from 1e-04 until 1e-14 with decrease of 0.01 for each successive step. The respective error from the equilibrium temperature $\left(75^{\circ} \mathrm{C}\right)$ was calculated and plotted as a function of the tolerance value in Figure 4. The temperature at the bottom was rounded off to two decimal places before calculating the error value. Once again, a random element towards the middle of the bottom surface was chosen for the calculation and the simulation time was increased to 300 s.

As expected, Figure 4 shows a reduction in error as the convergence tolerance is lowered and stabilises at 0 from 1e-08 onwards. The results were also corroborated by the time taken to reach the steady-state (Table 5) which reaches a constant value of 221 seconds from 1e-08 as well. Hence, it is believed that the selection of $1 \mathrm{e}-08$ would allow for more accurate simulation results. Although values lower than $1 \mathrm{e}-08$ could also be chosen, they would result in more number of iterations and hence, larger simulation times and resource consumption.

Therefore to identify the most efficient mesh size, convergence tolerance value of 1e-08 was used to run the previously described models and the updated time-temperature plots are shown in Figure 5. It is seen from the graphs that the models all reach $75^{\circ} \mathrm{C}$ thereby overcoming the initial problem of lower temperatures. However, the mesh sizes tested in the present work show similar temperature profiles with respect to time and cannot be differentiated from one another. It must also be noted that the $0.01 \mathrm{~m}$ mesh was not simulated for reasons identified previously. Therefore, the coarsest mesh was chosen to model future samples since it would consume the least resources and time. Additionally, the results also show the ineffectiveness of using hybrid meshes having different size perpendicular to and along the direction of heat flow is also shown in Figure 5.

According to the results presented in Figure 5, the selection of $0.001 \mathrm{~m}$ mesh size would seem the most logical solution for future models. However, since a $0.7 \mathrm{~mm}(0.0007 \mathrm{~m})$ coating was going to be applied onto the substrate, the mesh size needed to be smaller than the coating thickness since it is believed that a single element along a materials cross section would result in a slightly different temperature profile as compared to the others (see Figure 3 ). Therefore a 
mesh size of $0.00025 \mathrm{~m}$ was used for all future models. $0.0005 \mathrm{~m}$, although theoretically possibly, resulted in a single layer of elements due to the closeness of the mesh size to the coating thickness and hence was not considered.

To try and replicate the experimental setup described previously, two layers of coating were added to the top and bottom of the models as shown in Figure 6. This allowed a means of comparing the model with the experimental runs. To try and achieve this, three different temperatures- $50^{\circ} \mathrm{C}, 75^{\circ} \mathrm{C}$ and $100^{\circ} \mathrm{C}$ were applied to the nodes at the top surface similar to the experimental setup and the model was allowed to run for $1800 \mathrm{~s}$ ( 0.5 hours). The material properties for coating were defined according to Table 1 . The output at the bottom surface is the steady-state temperature (rounded off to two decimal places) of a single random element taken towards the centre of the bottom surface for each run. This result, along with the time taken to reach the steady state is reported in Table 6 for the runs of $0.00025 \mathrm{~m}$ model.

The results show that the temperature at the bottom of the specimen matches the input temperature for all three cases, thereby confirming the previous findings for this particular model and tolerance value. Further, the time taken to reach steady state conditions increases with the input temperature. Hence, these results demonstrate the validity of using the present model to simulate coated samples across the range of temperatures considered in the present study.

Finally, the results of the coated samples were compared with the experimental runs $1 \mathrm{C}$ and $1.5 \mathrm{C}$ as shown in Figure 7. The predictions of the FE model (shown as a line) were higher when compared to experimental results (markers). However, this is believed to be due to the absence of any heat loss effects such as air convection cooling in the model and the use of theoretical values in the models using the rule of mixtures (with the exception of the coating thermal conductivity) which, does not assume any resin infiltration into the aerogel. Additionally, although the temperature set in the experiment was as described previously, the actual readings at T1 (top thermocouple) were lower. Therefore when accounted for these differences, the model does represent a fair reproduction of the experiment showing the right linear trend between the temperatures.

\subsection{Model predictions}

The validated $0.00025 \mathrm{~m}$ model was then subjected to a load changing every 10 seconds between $50^{\circ} \mathrm{C}$ and $-50^{\circ} \mathrm{C}$ for 1800 seconds to determine the material's performance when using a cyclic temperature profile. These models had an initial temperature set to $23^{\circ} \mathrm{C}$ for all the nodes. Due to numerous reasons such as resource availability and/or economics, it may not always be possible to use a double layered coating. Therefore, the FE model with just the top coating and just the bottom coating were also simulated and compared.

Once again, the temperature of a single element towards the middle of the bottom surface is shown in Figure 8 as a function of time for the three different types of coatings. It is observed that the results of the three runs started at $23^{\circ} \mathrm{C}$ due to the initial temperature definition and attained equilibrium around $0^{\circ} \mathrm{C}$. However, the time at which they reached steady state varied with the type of coating used, with the double coating taking the longest at approximately 800 seconds and the bottom coating being quickest at around 200 seconds; the top coating was in between taking close to 600 seconds. Additionally, the bottom coating resulted in bigger 
fluctuations in temperature at steady state conditions and the double coating had the lowest; once again, the top coating's behaviour was in the middle.

\section{Discussion}

The thermal conductivity results in Table 3 show a decrease in the thermal conductivity between the pure epoxy samples and aerogel/epoxy samples. The percentage decrease compared to the pure epoxy coating is shown in Table 7 for the temperatures discussed in the present study wherein Coating $1 \mathrm{C}$ showed an average decrease of $40.7 \%$ decrease and $1.5 \mathrm{C}$ showed a $48.6 \%$ average decrease in thermal conductivity values. The existence of the aerogel particles with the nano-pores was also supported by the reflectance spectrums of the samples in the study which showed the presence of peaks at the 200-250nm interval for the aerogel coating. This peak was absent in the pure epoxy and the CFRP substrate samples. The reflectance spectrum of the aerogel coating also had a peak at $300 \mathrm{~nm}$ which is believed to be the result of the wetting agent. However, further research is needed to confirm this speculation.

When considering the FE simulations of the three types of coating, the double coating showed less variation in temperature at steady state compared to both single coating systems. But the latter attained equilibrium quicker than the former. Therefore, the choice of the coating system would depend on the specific requirement of the application. The double coating system would be preferred in environments where there are cyclic loads since the steady state is maintained at an almost constant temperature. Additionally, any change would be carried out at a slower rate resulting in a more comfortable environment for any living beings present. However, if a double coating system is not possible, a single top coating is advocated. But if there is a need to maintain the inside surface of the coating at a given bandwidth of temperature close to the equilibrium temperature in a randomised loading, then the single coating at the bottom is suggested.

However regardless of the coating system selected, the FE models do show an improvement in the thermal insulation performance of the material with an aerogel coating and recommends its usage. Nevertheless, it is believed that a more comprehensive model closer to experimental data is needed to make more accurate predictions. One possible route to achieving this, apart from accounting for the heat losses, would be the use of experimental data as input for the other properties where the resin infiltration into the nano-pores of the aerogel would also be accounted for.

\section{Conclusion}

The present study explored the possibility of using aerogel/epoxy composites as thermal insulation coatings on CFRP substrates. The reflectance spectrum and the thermal conductivity results showed evidence for the existence of the aerogel particles with limited resin infiltration. The thermal conductivity results showed a decrease of $40.7 \%$ and $48.6 \%$ for the samples wherein the aerogel was added after 1 hour and 1.5 hours respectively when compared with a pure epoxy coating. The aerogel based coating was also modelled and simulated using a finite element solver wherein the surface of its application affected the coating's performance. The double coating system showed the slowest rate of temperature change and the coating on the bottom surface had the fastest rate of drop. However, the latter showed the highest fluctuations at steady state with the former showing the least. The performance of the top coating was in- 
between when considering either parameter. Further research towards an improved model, particularly in the input of actual experimental values as material properties is suggested.

\section{Acknowledgements}

The authors would like to thank Mr. Jim Hurley, Mr. Andrew Stallard and Dr. Debabrata Bhattacharyya for assistance in the preparation of samples and equipment setup.

\section{References}

[1] Fitzer E, Gadow R. Fiber-reinforced silicon carbide. Am. Ceram. Soc. Bull. 1986;65:326-335.

[2] Buckley JD. Carbon-carbon, an overview. Ceram. Bull. 1988;67:364-368.

[3] Dhami TL, Bahl OP, Awasthy BR. Oxidation-Resistant Carbon-Carbon Composites Up To $1700^{\circ}$ C. Carbon N. Y. 1995;33:479-490.

[4] Gay D, Hoa S V. Composite Materials: Design and Applications. 2nd ed. Boca Raton, FL: CRC Press; 2007.

[5] Peel C. Advances in aerospace materials and structures. In: Cantor B, Assender H, Grant P, editors. Aerosp. Mater. Bristol: Institute of Physics Publishing; 2001. p. Chapter 9.

[6] Kistler SS. Coherent Expanded Aerogels and Jellies. Nature. 1931;127:741.

[7] Koravos J, Norwood C, Pescatore P, et al. Aerogel Insulative Coatings: New Coating Technology Offers Personnel Protection. Paint Coatings Ind. 2013 [cited 2016 Feb 12]. p. 48-50. Available from: http://www.pcimag.com/articles/98016-aerogel-insulativecoatings.

[8] Ge D, Yang L, Li Y, et al. Hydrophobic and thermal insulation properties of silica aerogel/epoxy composite. J. Non. Cryst. Solids. 2009;355:2610-2615.

[9] Kim SY, Noh YJ, Lim J, et al. Silica aerogel/polyimide composites with preserved aerogel pores using multi-step curing. Macromol. Res. 2014;22:108-111.

[10] Baetens R, Petter Jelle B, Gustavsen A. Aerogel insulation for building applications: A state-of-the-art review. Energy Build. 2011;43:761-769.

[11] Schmidt M, Schwertfeger F. Applications for silica aerogel products. J. Non. Cryst. Solids. 1998;225:364-368.

[12] Zhao JP, Ge DT, Zhang SL, et al. Studies on Thermal Property of Silica Aerogel/Epoxy Composite. Mater. Sci. Forum. 2007;546-549:1581-1584.

[13] Williams MK, Smith TM, Fesmire JE, et al. Aerogel/polymer composite materials. United States; [cited 2016 Jul 28]. Available from: http://www.google.co.uk/patents/US7790787.

[14] Allan JM, Mumin MA, Wood JA, et al. Silica aerogel-poly(ethylene-co-vinyl acetate) composite for transparent heat retention films. J. Polym. Sci. Part B Polym. Phys. 2014;52:927-935.

[15] Achar S, Procopio LJ. Developments in waterborne thermal insulation coatings. J. 
Prot. Coatings Linings. 2013;30:48-59.

[16] Vahtrus M, Oras S, Antsov M, et al. Mechanical and thermal properties of epoxy composite thermal insulators filled with silica aerogel and hollow glass microspheres. Proc. Est. Acad. Sci. 2017;66:339-346.

[17] Gupta N, Ricci W. Processing and compressive properties of aerogel/epoxy composites. J. Mater. Process. Technol. 2008;198:178-182.

[18] Basri MSM, Mazlan N, Mustapha F. Effects of stirring speed and time on water absorption performance of silica aerogel/epoxy nanocomposite. ARPN J. Eng. Appl. Sci. 2015;10:9982-9991.

[19] Kandola BK, Bhatti W, Kandare E. A comparative study on the efficacy of varied surface coatings in fireproofing glass/epoxy composites. Polym. Degrad. Stab. 2012;97:2418-2427.

[20] Luangtriratana P, Kandola BK, Myler P. Ceramic particulate thermal barrier surface coatings for glass fibre-reinforced epoxy composites. Mater. Des. 2015;68:232-244.

[21] Ivankovic M, Brnardic I, Ivankovic H, et al. DSC study of the cure kinetics during nanocomposite formation: Epoxy/poly(oxypropylene) diamine/organically modified montmorillonite system. J. Appl. Polym. Sci. 2006;99:550-557.

[22] Hayaty M, Beheshty MH, Esfandeh M. Isothermal differential scanning calorimetry study of a glass/epoxy prepreg. Polym. Adv. Technol. 2011;22:1001-1006.

[23] Poisson N, Lachenal G, Sautereau H. Near-and mid-infrared spectroscopy studies of an epoxy reactive system. Vib. Spectrosc. 1996;12:237-247.

[24] Çengel YA. Introduction to Thermodynamics and Heat Transfer. New York: McGrawHill; 1997.

[25] Krishnaswamy S, Bhattacharyya D, Abhyankar H, et al. Morphological, optical and thermal characterisation of aerogel-epoxy composites for enhanced thermal insulation. J. Compos. Mater. 2018.

[26] Shapiro AB. Heat Transfer in LS-DYNA. 4th Eur. LS-DYNA Users Conf. Ulm, Germany; 2003. p. H-I01-08.

[27] Tobias Erhart. Review of Solid Element Formulations in LS-DYNA. Entwicklerforum. 2011 [cited 2018 Feb 6]. Available from:

https://www.dynamore.de/de/download/papers/forum11/entwicklerforum2011/erhart.pdf.

[28] LSTC. LS-DYNA® Keyword user’s Manual I- version R8.0. 2015.

[29] Fernandes CD, Bridges JC, Grady MM. UV And Visible Wavelength Reflectance Spectroscopy Of Aerogel And Of Stardust Grains. Lunar Planet. Sci. 2007;XXXVIII.

[30] Physik Instrumente. Piezo Ceramic Materials and Products. Piezo Mater. Components. 2011 [cited 2018 Jan 2]. Available from: http://www.piezo.ws/pdf/Piezo_Materials_Piezo_Technology_Piezo_Components.pdf.

[31] ASM Committee on Forms and Properties of Composite Materials. High-Strength Medium-Temperature Thermoset Matrix Composites. In: ASM International Handbook Committee, editor. Eng. Mater. Handb. Vol. 1. Ohio: ASM International; 
1987.

[32] Cabot Corporation. Enova Aerogel Fine Particles. Saf. Data Sheet. Cabot Corporation; 2012 [cited 2016 Aug 8]. p. 1-8. Available from: http://www.buyaerogel.com/wpcontent/uploads/2014/02/NGFPA-EUR-EN.pdf.

[33] PRF Composites. Ultra Low Viscosity Epoxy Resin System RS-M135. Prod. Data Sheet. 2013 [cited 2017 Oct 13]. Available from: http://www.prfcomposites.com/store/image/data/PDF/RS-M135.pdf.

[34] Active Space Technologies. Aerogels - Product Datsheet at Active Space Technologies. Futur. Therm. Insul. Sp. Appl. 2011 [cited 2018 Feb 2]. Available from: http://esther.ist.utl.pt/pages/yurisnight2011/ActiveSpaceTech.pdf. 
Table 1 Material Card Properties. The sources of the values are given in the brackets next to their respective values.

\begin{tabular}{|c|c|c|c|}
\hline Property & Substrate & \multicolumn{2}{|c|}{ Coating } \\
\hline \multirow{3}{*}{ Density $\left(\mathrm{kg} / \mathrm{m}^{3}\right)$} & \multirow{3}{*}{$1460[31]$} & Aerogel & $135[32]$ \\
\hline & & Epoxy & $1190[33]$ \\
\hline & & Coating & 968.45 \\
\hline \multirow{3}{*}{ Heat Capacity $(\mathrm{J} /(\mathrm{kg} * \mathrm{~K})$} & \multirow{3}{*}{$1170[31]$} & Aerogel & $2100[34]$ \\
\hline & & Epoxy & $1890[31]$ \\
\hline & & Coating & 1934.1 \\
\hline $\begin{array}{l}\text { Thermal Conductivity (Axial) } \\
\left(\mathrm{W} /\left(\mathrm{m}^{*} \mathrm{~K}\right)\right)\end{array}$ & $14.57[31]$ & \multirow{2}{*}{\multicolumn{2}{|c|}{0.20015 [25] }} \\
\hline $\begin{array}{l}\text { Thermal Conductivity (Transverse) } \\
\qquad(\mathrm{W} /(\mathrm{m} * \mathrm{~K}))\end{array}$ & $0.75[31]$ & & \\
\hline
\end{tabular}

Table 2 Heat flow across the standard at different temperatures

\begin{tabular}{|c|c|c|c|c|c|}
\hline $\begin{array}{c}\text { Temperature } \\
\left({ }^{0} \mathrm{C}\right)\end{array}$ & Run & $\begin{array}{c}\mathrm{T} 1 \\
\left({ }^{0} \mathrm{C}\right) \\
\end{array}$ & $\begin{array}{r}\mathrm{T} 2 \\
\left({ }^{\circ} \mathrm{C}\right) \\
\end{array}$ & $\begin{array}{c}\text { dT } \\
\left({ }^{\circ} \mathrm{C}\right) \\
\end{array}$ & $\begin{array}{c}\mathbf{q} \\
(\mathbf{W}) \\
\end{array}$ \\
\hline \multirow{4}{*}{50} & 1 & 44.7 & 41.8 & 2.9 & 0.72 \\
\hline & 2 & 45 & 41.8 & 3.2 & 0.79 \\
\hline & 3 & 44.2 & 40.9 & 3.3 & 0.82 \\
\hline & \multicolumn{4}{|c|}{ Average } & 0.78 \\
\hline \multirow{4}{*}{75} & 1 & 65.5 & 59.6 & 5.9 & 1.46 \\
\hline & 2 & 65.7 & 59.5 & 6.2 & 1.53 \\
\hline & 3 & 65.1 & 58.7 & 6.4 & 1.58 \\
\hline & \multicolumn{4}{|c|}{ Average } & 1.53 \\
\hline \multirow{4}{*}{100} & 1 & 86.6 & 77.7 & 8.9 & 2.20 \\
\hline & 2 & 86.8 & 77.5 & 9.3 & 2.30 \\
\hline & 3 & 86.3 & 76.9 & 9.4 & 2.33 \\
\hline & \multicolumn{4}{|c|}{ Average } & 2.28 \\
\hline
\end{tabular}


Table 3 Thermal Conductivity values for the samples at different temperatures

\begin{tabular}{|c|c|c|c|c|c|c|}
\hline \multirow{3}{*}{ Sample } & \multicolumn{6}{|c|}{ Thermal Conductivity } \\
\hline & \multicolumn{2}{|c|}{$50^{0} \mathrm{C}$} & \multicolumn{2}{|c|}{$75^{\circ} \mathrm{C}$} & \multicolumn{2}{|c|}{$100^{\circ} \mathrm{C}$} \\
\hline & $\begin{array}{l}\mathbf{d T} \\
(\mathbf{K})\end{array}$ & $\begin{array}{c}\mathbf{k} \\
\left(\mathbf{W} /\left(\mathbf{m}^{*} \mathbf{K}\right)\right)\end{array}$ & $\begin{array}{l}\mathbf{d T} \\
(\mathbf{K})\end{array}$ & $\begin{array}{c}\mathbf{k} \\
(\mathbf{W} /(\mathbf{m} * \mathbf{K}))\end{array}$ & $\begin{array}{l}\mathbf{d T} \\
(\mathbf{K})\end{array}$ & $\begin{array}{c}\mathbf{k} \\
(\mathbf{W} /(\mathbf{m} * \mathbf{K}))\end{array}$ \\
\hline \multirow{7}{*}{$\begin{array}{c}\text { Pure Epoxy Coating } \\
\text { (P) }\end{array}$} & 6.4 & 0.67 & 11.9 & 0.71 & 17.8 & 0.70 \\
\hline & 7.2 & 0.59 & 12.8 & 0.66 & 18.8 & 0.66 \\
\hline & 6.1 & 0.72 & 11.7 & 0.74 & 17.6 & 0.73 \\
\hline & 6.4 & 0.65 & 11.8 & 0.69 & 17.5 & 0.70 \\
\hline & 6.2 & 0.65 & 12.1 & 0.65 & 18 & 0.65 \\
\hline & Average & 0.66 & Average & 0.69 & Average & 0.69 \\
\hline & $\sigma$ & 0.047 & $\sigma$ & 0.037 & $\sigma$ & $\mathbf{0 . 0 3 3}$ \\
\hline \multirow{7}{*}{$\begin{array}{c}1 \text { Hour } \\
\text { Aerogel/Epoxy } \\
\text { Coating }(1 \mathrm{C})\end{array}$} & 14.5 & 0.35 & 26.9 & 0.36 & 39.5 & 0.37 \\
\hline & 13.8 & 0.39 & 24.7 & 0.43 & 35.3 & 0.45 \\
\hline & 13.6 & 0.42 & 24.6 & 0.45 & 35.3 & 0.47 \\
\hline & 15.2 & 0.36 & 27.5 & 0.39 & 39.9 & 0.40 \\
\hline & 14.1 & 0.38 & 26.4 & 0.40 & 37.7 & 0.41 \\
\hline & Average & 0.38 & Average & 0.41 & Average & 0.42 \\
\hline & $\sigma$ & 0.027 & $\sigma$ & 0.035 & $\sigma$ & 0.040 \\
\hline \multirow{7}{*}{$\begin{array}{c}1.5 \text { Hour } \\
\text { Aerogel/Epoxy } \\
\text { Coating }(1.5 \mathrm{C})\end{array}$} & 15.9 & 0.33 & 27.1 & 0.38 & 39.5 & 0.39 \\
\hline & 15.2 & 0.36 & 28.2 & 0.38 & 41.1 & 0.39 \\
\hline & 17.8 & 0.29 & 30.1 & 0.34 & 44 & 0.35 \\
\hline & 16.9 & 0.31 & 29.5 & 0.35 & 41.9 & 0.36 \\
\hline & 17.6 & 0.31 & 32 & 0.33 & 45.9 & 0.34 \\
\hline & Average & 0.32 & Average & 0.36 & Average & 0.37 \\
\hline & $\sigma$ & 0.026 & $\sigma$ & 0.023 & $\sigma$ & 0.023 \\
\hline
\end{tabular}

Table 4 Steady state temperatures for different mesh sizes

\begin{tabular}{|c|c|}
\hline $\begin{array}{c}\text { Mesh size } \\
(\mathbf{m})\end{array}$ & $\begin{array}{c}\text { Steady state temperature } \\
\left({ }^{\mathbf{0}} \mathbf{C}\right)\end{array}$ \\
\hline 0.01 & 73.51 \\
\hline 0.001 & 72.55 \\
\hline Hybrid & 72.49 \\
\hline 0.0005 & 71.35 \\
\hline 0.00025 & 67.99 \\
\hline 0.0001 & 54.22 \\
\hline
\end{tabular}


Table 5 Steady state temperature times for different convergence tolerance values

\begin{tabular}{|c|c|}
\hline Convergence Tolerance & $\begin{array}{c}\text { Time to reach steady state } \\
(\mathbf{s})\end{array}$ \\
\hline $1.00 \mathrm{E}-04$ & 81 \\
\hline $1.00 \mathrm{E}-06$ & 177 \\
\hline $1.00 \mathrm{E}-08$ & 221 \\
\hline $1.00 \mathrm{E}-10$ & 221 \\
\hline $1.00 \mathrm{E}-12$ & 221 \\
\hline $1.00 \mathrm{E}-14$ & 221 \\
\hline
\end{tabular}

Table 6 Surface temperature of coated models

\begin{tabular}{|c|c|c|c|}
\hline \multirow{2}{*}{ Element size } & $\begin{array}{c}\text { Temperature on } \\
\text { the top surface } \\
\left({ }^{\mathbf{0}} \mathbf{C}\right)\end{array}$ & $\begin{array}{c}\text { Temperature on } \\
\text { the bottom surface } \\
\left({ }^{\mathbf{0}} \mathbf{C}\right)\end{array}$ & $\begin{array}{c}\text { Time to reach } \\
\text { steady state } \\
(\mathbf{s})\end{array}$ \\
\hline \multirow{3}{*}{0.00025} & 50 & 50 & 1419 \\
\cline { 2 - 4 } & 75 & 75 & 1525 \\
\cline { 2 - 4 } & 100 & 100 & 1589 \\
\hline
\end{tabular}

Table 7 Percentage decrease of the aerogel/epoxy coated samples

\begin{tabular}{|l|l|l|l|l|}
\hline Sample & $\mathbf{5 0}^{\mathbf{0}} \mathbf{C}$ & $\mathbf{7 5}^{\mathbf{0}} \mathbf{C}$ & $\mathbf{1 0 0}^{\mathbf{0}} \mathbf{C}$ & Average \\
\hline $1 \mathrm{C}$ & 42.4 & 40.6 & 39.1 & $\mathbf{4 0 . 7}$ \\
\hline $1.5 \mathrm{C}$ & 51.5 & 47.8 & 46.4 & $\mathbf{4 8 . 6}$ \\
\hline
\end{tabular}




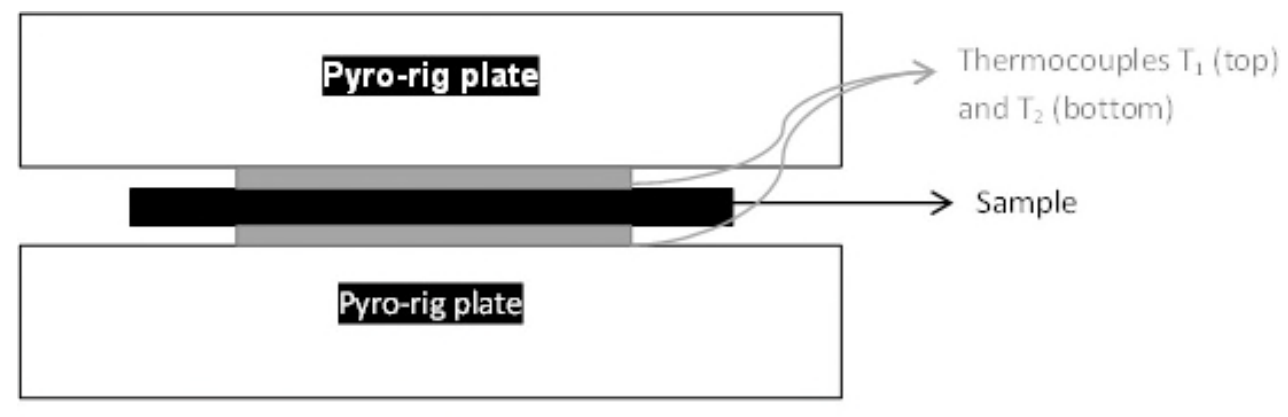

(a)

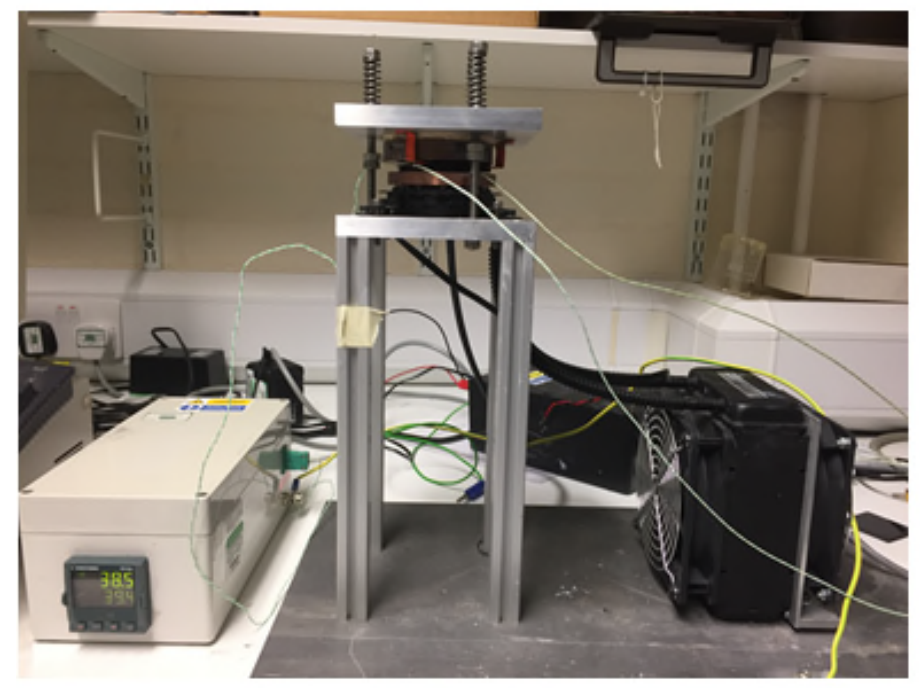

(b)

Figure 1 (a) labelled diagram of the heating setup; (b) Image of the pyro heater setup along with the controller 


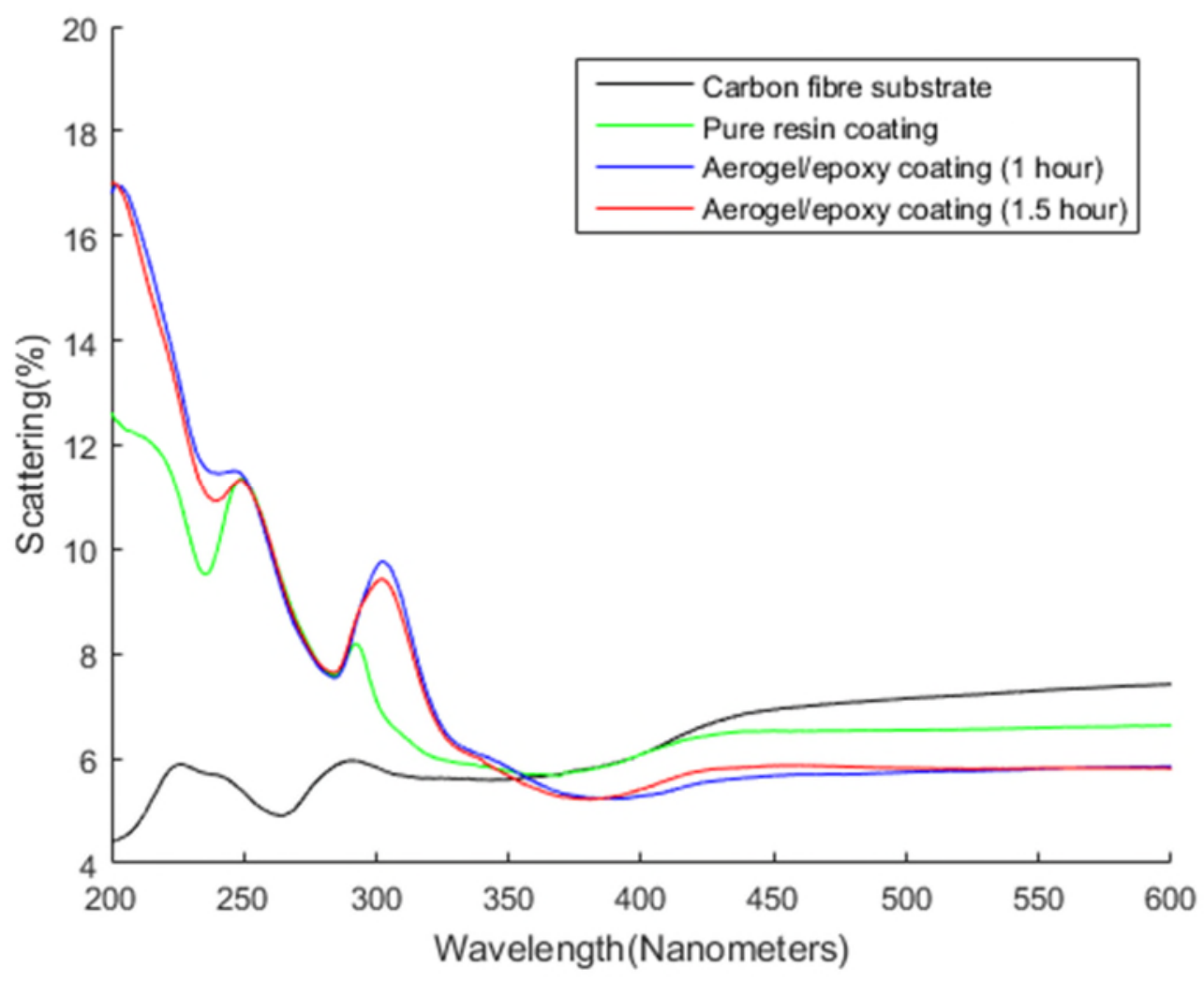

Figure 2 Scattering plot for the samples

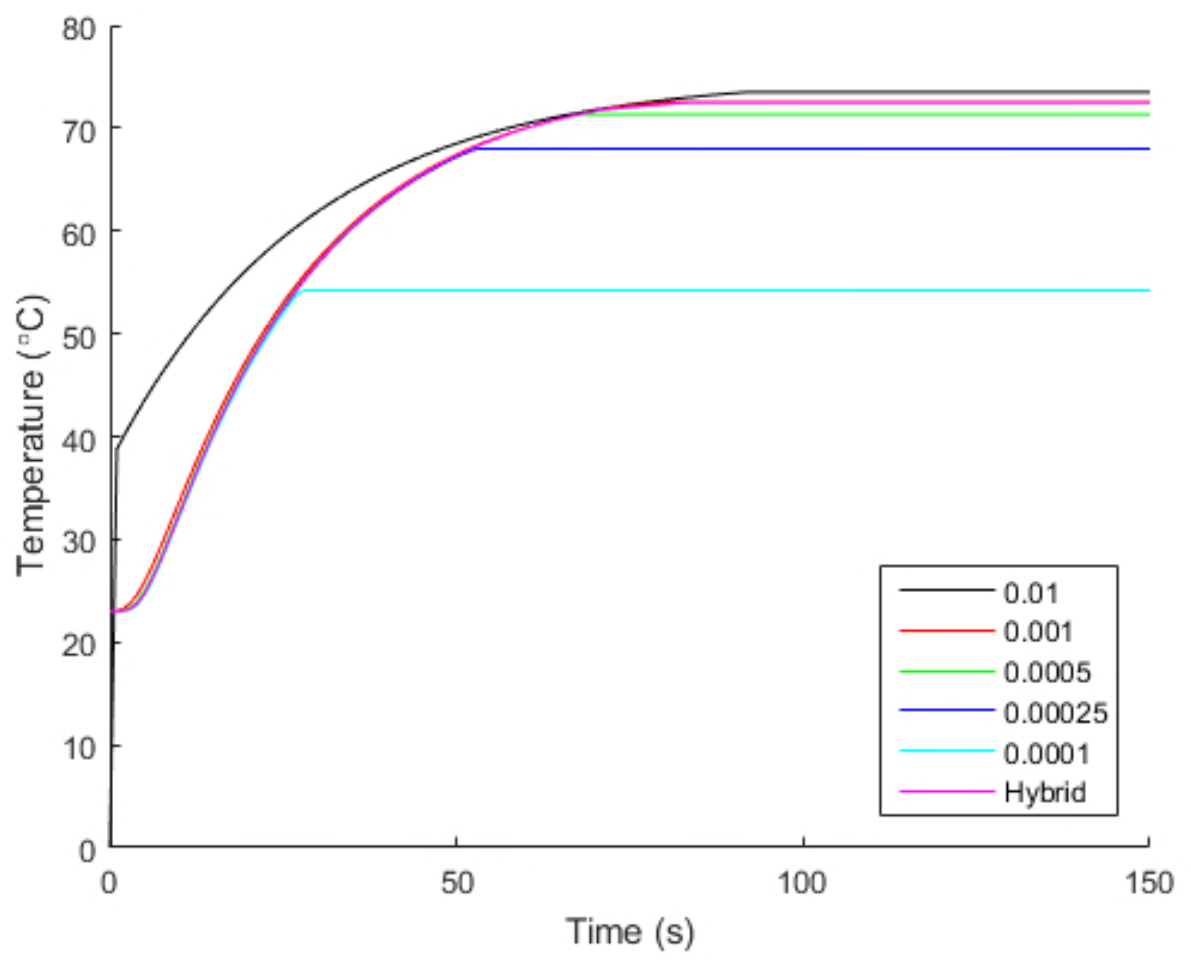

Figure 3 Mesh size comparison (sizes in m) 


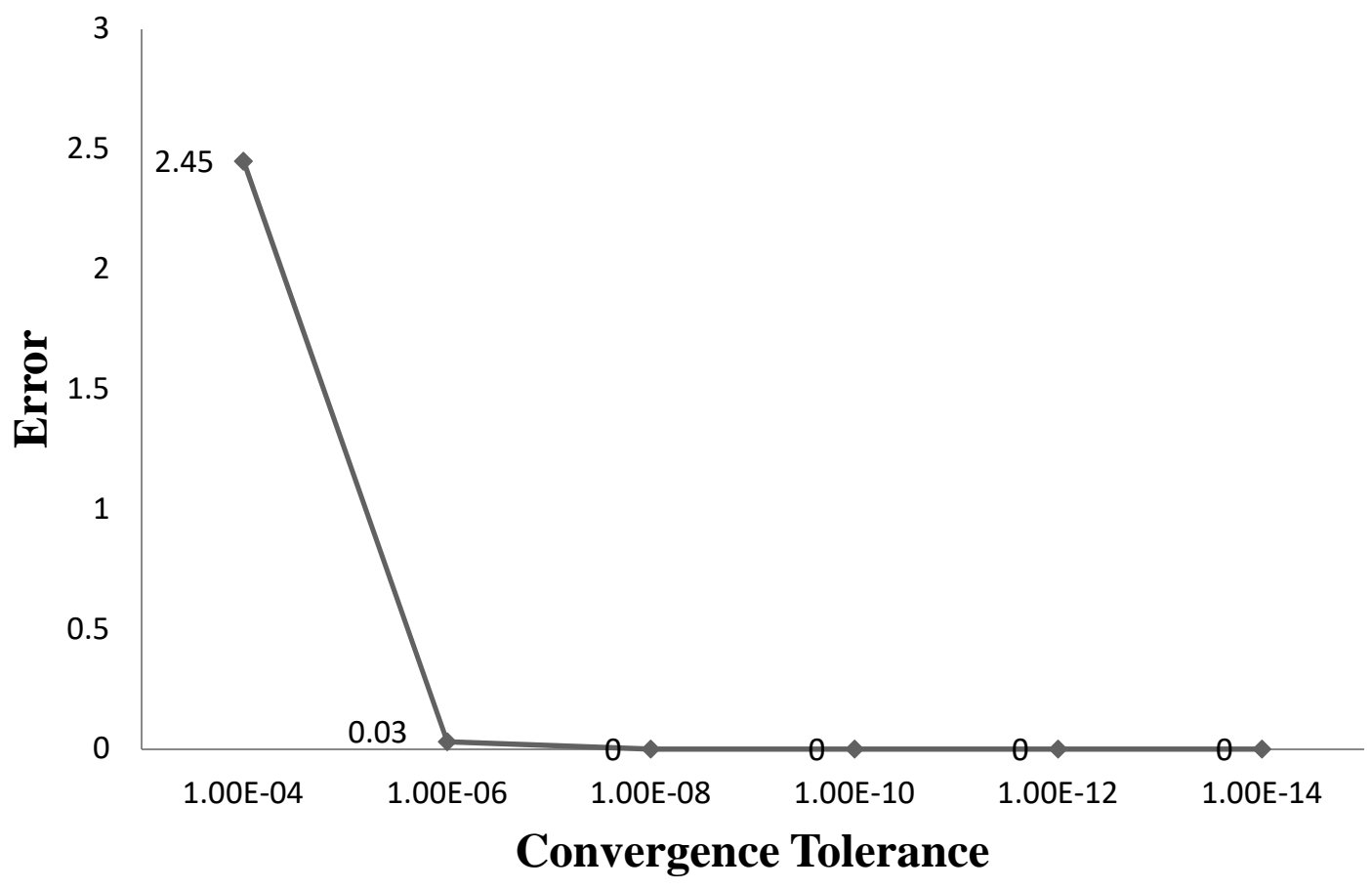

Figure 4 Simulation error as a function of convergence tolerance

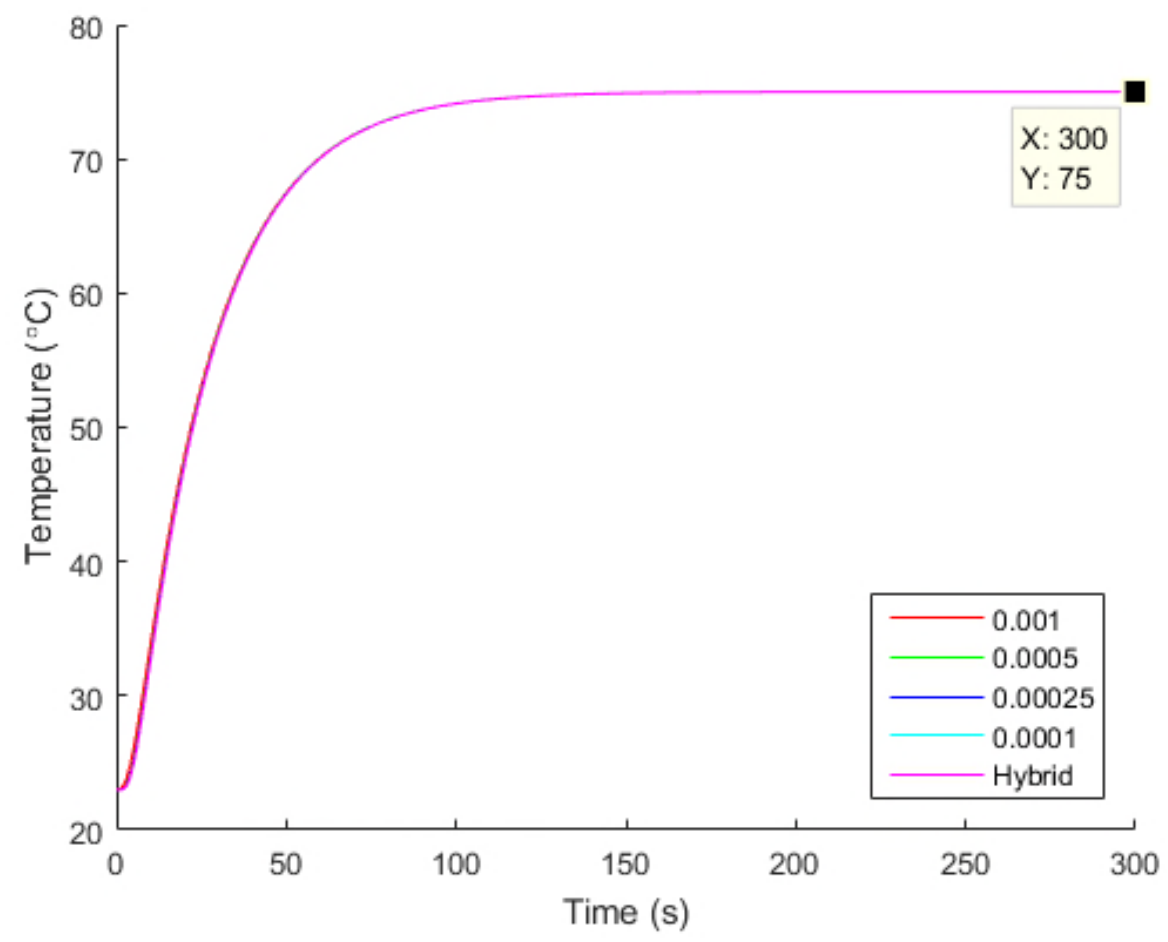

Figure 5 Updated mesh size comparison with a convergence tolerance value of 1e-08 


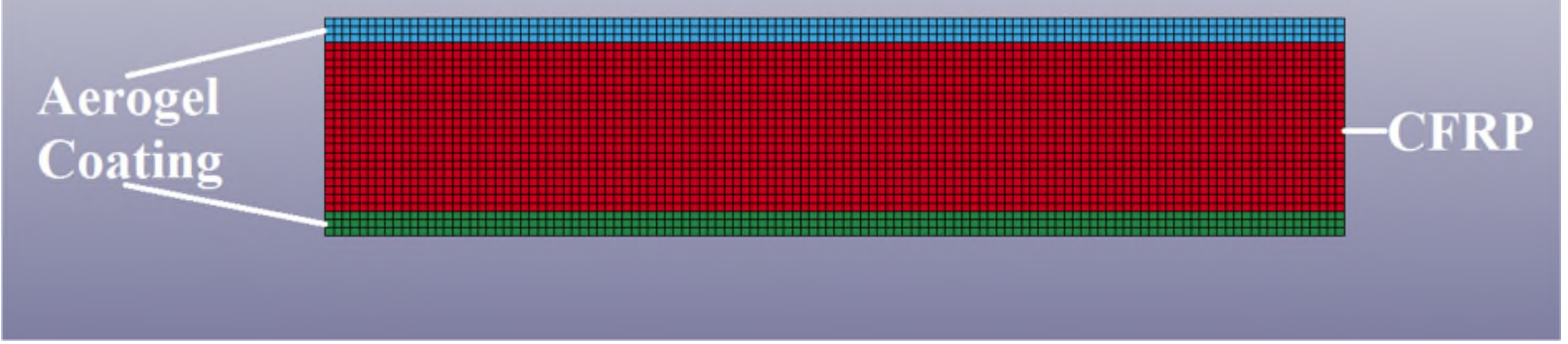

Figure 6 Sectional view of the coated sample

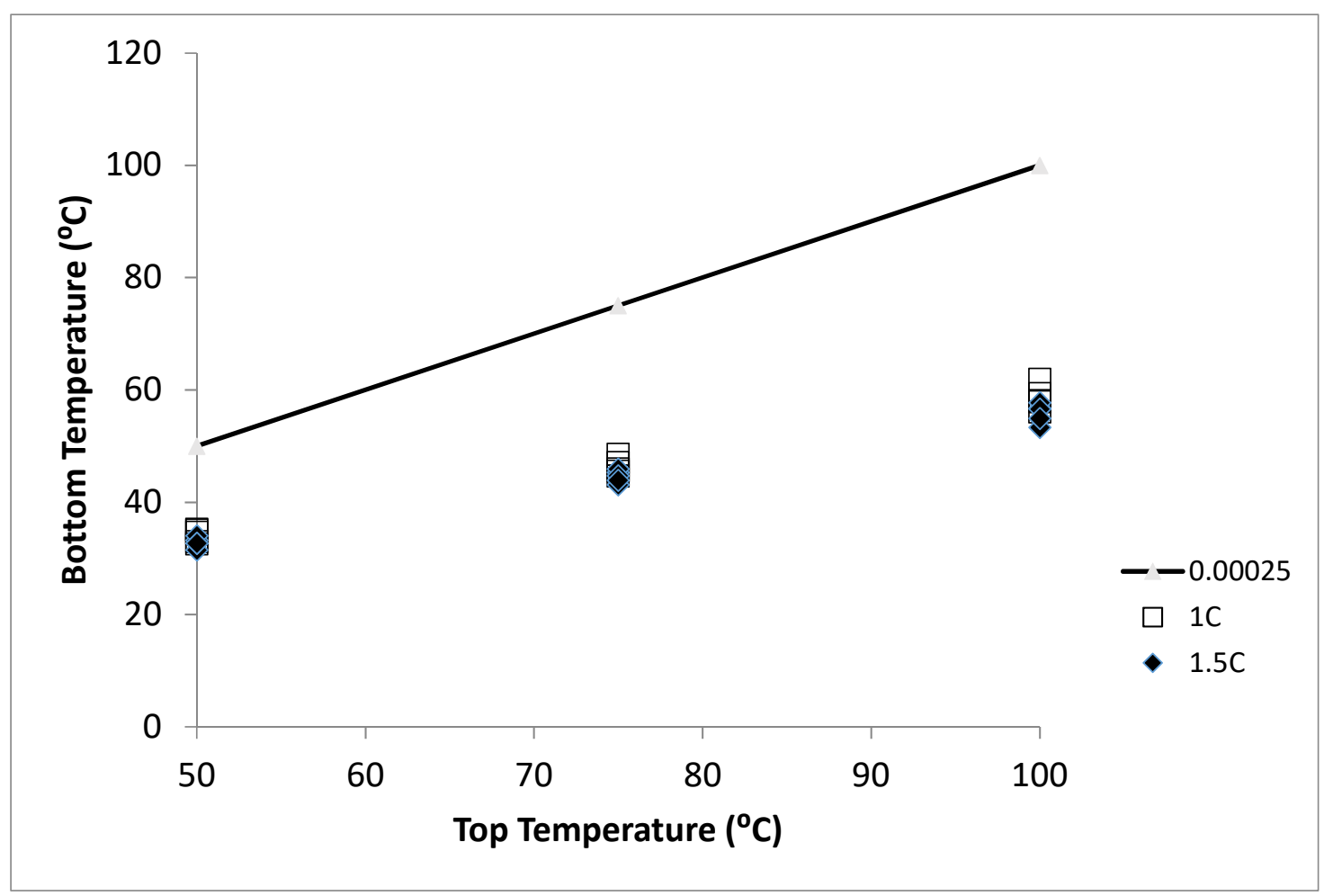

Figure 7 Comparison of FE and experimental data 


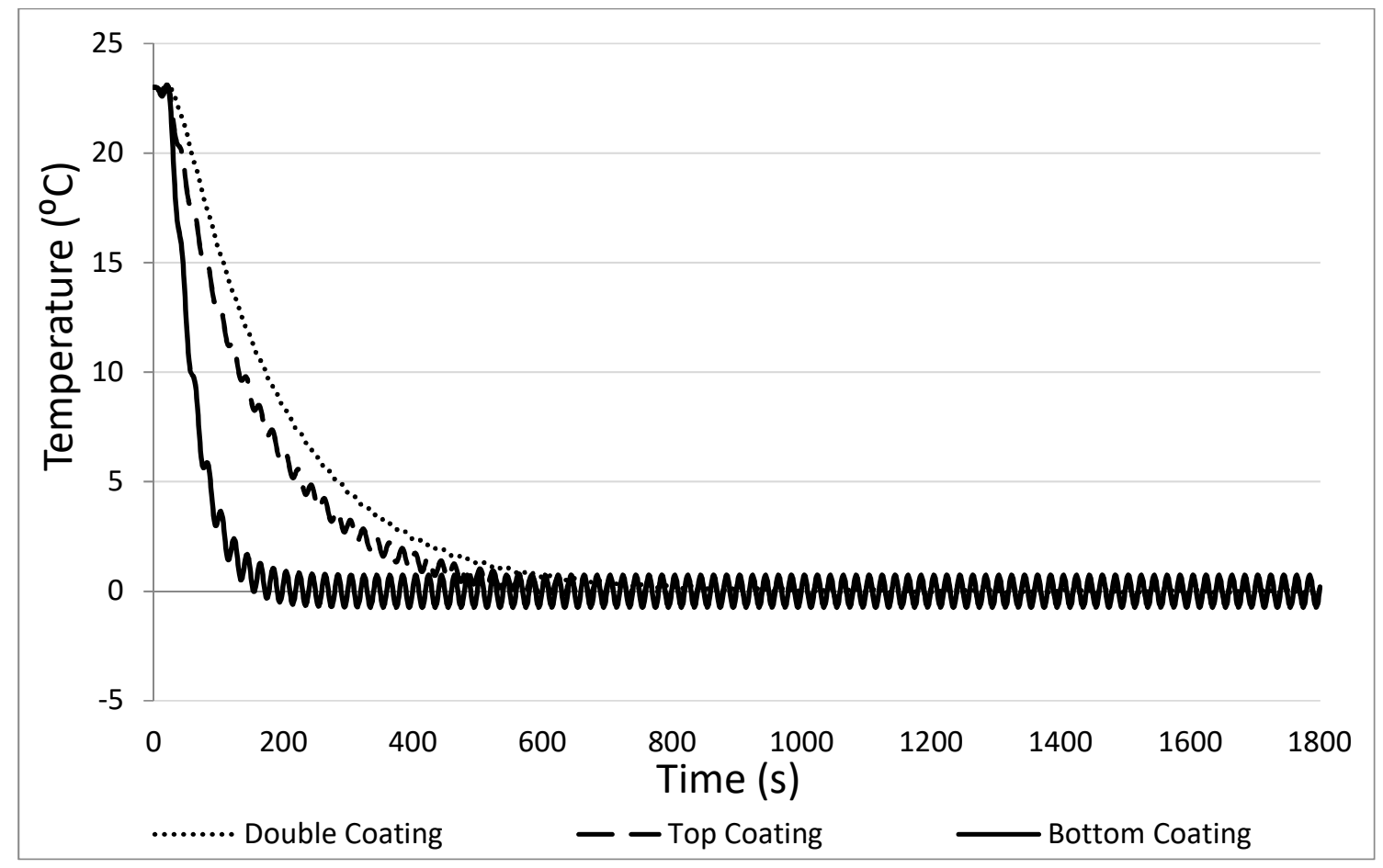

Figure 8 Performance of different coating types with a cyclic temperature load 
2019-01-20

\section{Aerogel/epoxy thermal coatings for carbon fibre reinforced plastic substrates}

Krishnaswamy, Suryanarayanan

Taylor and Francis

Krishnaswamy S, Abhyankar HA, Marchante V, et al., (2019) Aerogel/epoxy thermal coatings for carbon fibre reinforced plastic substrates, Journal of Adhesion Science and Technology, Volume 33, Issue 6, 2019, pp. 579-594

https://doi.org/10.1080/01694243.2018.1558476

Downloaded from Cranfield Library Services E-Repository 